\title{
O REFLEXO DA IDEOLOGIA DOMINANTE NO POSICIONAMENTO DO ESTUDANTE DE ENFERMAGEM FRENTE AO ABORTO
}

Rosa Maria Godoy Serpa da Fonseca*

Emiko Yoshikawa Egry*

FONSECA, R. M. G. S. da; EGRY, E. Y. O reflexo da ideologia dominante no posicionamento do estudante de enfermagem frente ao aborto. Rev. Esc. Enf. USP, v.28, n.1, p. 50-8, Abril, 1994.

As autoras re-analisam, sob novo prisma, os resultados de duas investigacóes realizadas acerca do posicionamento do estudante de enfermagem diante do aborto. Discutem as questōes e limites metodológicos destas investigaçöes bem como apontam a necessidade de se buscar a compreensão da temática de forma mais ampliada, ou seja, através da articulaçāo com a ideologia dominante.

UNITERMOS: aborto, ideologia, ensino de enfermagem.

\section{INTRODUÇÃo}

A prática do aborto** como controlador da natalidade vem sendo utilizada por diferentes grupos sociais em diferentes momentos históricos assumindo, inicialmente, um caráter de legalidade e proteção da vida já existente para, posteriormente, e até nossos dias, especialmente nas sociedades ocidentais, assumir o caráter de ilegalidade e criminalidade.

Nas sociedades primitivas, especialmente entre os povos nômades, práticas como o aborto e o infanticídio serviam como controladores demográficos, com o objetivo primordial de manter o equilibrio entre o tamanho e a conformaçāo grupal (quantidade de pessoas produtivas e dependentes do grupo) e a possibilidade de acesso ao alimento disponivel (GREER, 1987).

A partir do momento em que o homem passou a controlar a natureza, exercendo atividades agro-pastoris, portanto, fixando-se na terra, já não havia grandes preocupaçōes em relação ao controle populacional, uma vez que ele agora, detinha o poder de produzir a quantidade de alimento necessário. Pelo contrário, deste momento em diante, o importante era o cresci-

Enfermeira. Profeaseor Doulor do Departamento de Enfermagem em Saúde Coletiva da Escola de Enfermagem da Univernidade de Sảo Paulo

- Por aborto neste trabalho encendemos a interrupç̧ấo doloes da gravidez. Vide Aurélio Buarque de Hollanda Ferreira, Novo Dicionário da Lingua Portuguea, p. 12. 
mento dos grupamentos sociais com o fito de manter a soberania econômica do Estado emergente.

Determinada pelo económico, a política demográfica passou a assumir então, um caráter francamente pró-natalista e a superestrutura social, para legitimar este caráter, passou a desenvolver e reproduzir uma ideologia que proibia e condenava estas práticas controladoras da natalidade, sob argumentos humanitários e religiosos.

Esta foi a postura das sociedades de classes cujos sistemas econômicos necessitavam de grande quantidade de força de trabalho, especialmente das classes dominadas, como forma de manter a dominação tanto de uma classe sobre a outra como de um Estado sobre o outro, como por exemplo, o escravagismo, o feudalismo e as formas primitivas do capitalismo (GREER, 1987).

Com o desenvolvimento do capitalismo, o que passou a interessar não foi mais a quantidade, mas a qualidade da força de trabalho, sem que as classes dominadoras perdessem a capacidade de manter a dominação sobre as demais. O que passou a existir então, foi uma política de controle da natalidade que, no entanto, para não ferir os valores humanitários e religiosos desenvolvidos anteriormente, explicitaria a defesa deste controle sob a forma de anticoncepção. Até nossos dias, sob a alegação de que com isto não destrói a vida mas apenas controla o potencial de vida, esta política desenvolve e estimula o uso de métodos anticoncepcionais eficazes mesmo com prejuízo para a saúde do usuário.

Este usuário, no caso, se trata da mulher pobre, que sofre dupla dominação, de classe e gênero já que este tipo de sociedade, é além de tudo, controlada por homens, portanto patriarcal e machista (OLIVEIRA, 1989).

A prática do aborto, embora legalmente proibida e condenada, na realidade é acessivel a todas as mulheres, independentemente da sua classe, diferenciando apenas a qualidade da assistência prestada de acordo com a sua inserção social. O Código Civil Brasileiro e os Códigos de Ética Profissional (Médico, de Enfermagem) prevêm penas, tanto para as gestantes que procuram este recurso como para os profissionais envolvidos (médicos, enfermeiros, farmacêuticos, etc). Por outro lado, enquanto a mulher da classe dominante tem acesso aos métodos abortivos mais modernos com o uso de equipamentos e pessoal altamente especializado, em clínicas que dificilmente colocam em risco a sua "integridade moral", à mulher da classe dominada resta, em geral, recorrer aos exercentes da medicina popular que muitas vezes empregam métodos que colocam em risco a sua saúde podendo levá-la até à morte. Além disso tem que sujeitar-se às mais diversas formas de punição, no caso de ser descoberta pelas autoridades jurídicas competentes.

Este trabalho tem o objetivo de repensar criticamente os resultados de duas pesquisas (EGRY, 1985 e FONSECA, 1985) realizadas entre estudantes do Curso de Graduaçāo em Enfermagem da Escola de Enfermagem da Universidade de São Paulo, um conjunto de ingressantes e outro de formandos, sobre o posicionamento individual dos mesmos em relação à prática do aborto, assumindo que estes posicionamentos podem refletir as concepçöes ideológicas das classes sociais a que pertencem estes estudantes. 
As autoras reconhecem que a metodologia utilizada, o inquérito tipo "survey" baseado em pressupostos positivistas, nāo permite conclusōes acerca da determinação social destes posicionamentos, não sendo suficiente para estabelecer as conexōes existentes entre os processos estrutura is (globais) da sociedade e a manifestação individual. No entanto, consideram que pode ser uma chamada à problemática que cerca o aborto como prática social e, portanto, servir de subsídio para repensar o papel do órgảo formador em relação a estimular e desenvolver o potencial de critica do estudante sobre a realidade em que irá atuar quando profissional.

Apesar destas pesquisas terem sido realizadas já há algum tempo (final de 1984 e inicio de 1985), acreditam que podem refletir, ainda que em parte, os valores atuais das classes sociais envolvidas, uma vez que as transformações nos valores demandam tempo para acontecer, tempo este certamente muito maior que o decorrido entre a coleta dos dados das duas investigaçóes e a atual reinterpretaçāo dos mesmos.

\section{RESULTADOS E COMENTÁRIOS}

Além das limitaçōes explicitadas anteriormente, em relação à metodologia utilizada na pesquisa, antes de se passar à análise dos seus resultados, há que se tecer algumas consideraçōes sobre a divisão da sociedade em classes sociais e $a$ inserção do estudante universitário brasileiro hoje nestas classes. Este exercício teórico visa tentar entender um pouco melhor as conexōes entre os processos sociais globais e os individuais.

Segundo BRONFMAN; TUIRÁN (1984), "o conceito de classe social surge, sob a ótica do materialismo histórico e dialético, ao nivel de análise específica de um determinado modo de produçāo. Em um primeiro momento, as classes aparecem como a personificação das categorias econômicas fundamentais de cada modo de produção, as que, por sua vez, expressam relaçōes específicas que os homens estabelecem com os objetos e os meios de trabalho e, por este caminho, entre eles, no processo de produção social de bens materiais. Daí que as classes se distinguem entre si pela posiçāo que ocupam nas relações sociais de produção e, mais especificamente, nas relaçōes de exploraçāo, o qual imprime um caráter antagônico às relaçōes entre as classes."

Portanto, por este conceito se depreende que as classes sociais se situam não só pela posição que ocupam na instância econômica, senão também por sua consciência e presença política. Entende-se a sociedade formada por uma base estrutural económica sobre a qual se ergue uma superestrutura jurídico-político-ideológica cuja principal função é reproduzir e sustentar o sistema econômico, legitimando as relaçōes sociais de produção, ou seja, as relaçōes entre as classes sociais.

Nesta estrutura social, o papel das classes em relação à ideologia é definido a partir dessas concepçōes, ou seja, à burguesia, como classe dominante, proprietária dos meios de produção, cabe produzir a ideologia que 
legitima as relaçōes de exploração e assim manter esta relação. Às classes dominadas (proletariado e sub-proletariado) cabe acatar esta ideologia e produzir uma contra-ideologia através da qual antagonize as classes dominantes, estabelecendo uma relação dialética que dá movimento ao todo social. Entre estas duas classes básicas situa-se a nova pequena burguesia, cujo papel é a reprodução e transmissāo da ideologia das classes dominantes, uma vez que se encontra a seu serviço (FONSECA, 1990).

Nesta classe social situam-se os trabalhadores detentores do saber técnico especializado, que ocupam os postos de mais alto nível técnico e de tomada de decisóes, cujo papel além de transmissor e reprodutor da ideologia dominante é o de organizar a exploração da força de trabalho das classes dominadas. Ao desempenhar satisfatoriamente seu papel, a nova pequena burguesia garante a sua sobrevivência enquanto classe (FONSECA, 1990).

Dado que a universidade estatal brasileira, historicamente, foi instituída a serviço das classes dominantes, têm acesso ao conhecimento produzido no seu interior, geralmente, as pessoas provenientes destas classes sociais, portanto, representantes da burguesia ou nova pequena burguesia. Ao se graduar, por sua vez, garantem a reproduçāo social destas classes, já que a elas continuam a pertencer ou pela detençāo dos meios produtivos (burguesia) ou pela detençáo do conhecimento adquirido (nova pequena burguesia).

Utilizando uma operacionalizaçāo de classe social, a partir dos elementos contidos na definiçāo de Lenin e cujo valor analítico tem sido reiteradamente comprovado em vários estudos sobre determinação dos fenômenos sociais (FONSECA, 1990; OLIVEIRA, 1988; BERTOLOZZI, 1991; LOMBARDI, 1988) recentemente, em 1990, procedemos à classificaçāo social de estudantes do penúltimo semestre do curso de Graduação em Enfermagem, com o objetivo de confirmar empiricamente a afirmação anterior.

De fato, a maioria pertencia às classes sociais dominantes, $71,42 \%$ (representadas pela burguesia e nova pequena burguesia), incluindo-se nesta proporçāo $19,04 \%$ representantes da pequena burguesia tradicional, classe social que se configura como quase autónoma no modo de produção capitalista, já que é representada por unidade de produção praticamente autosuficientes, familiares ou de pequenos proprietários. Dos $23,80 \%$ restantes que pertenciam ao proletariado, dois terços exerciam atividades de mando situando-se, portanto, muito próximo da nova burguesia na hierarquia social.

Apesar de haver uma defasagem de 5 anos entre este estudo sobre a classificação social e os demais sobre o posicionamento dos estudantes frente ao aborto, as autoras consideram que os seus resultados podem ser relacionados, dado que o perfil ideológico dos estudantes nāo se transforma em tāo pouco tempo.

\section{O posicionamento dos ingressantes sobre o aborto}

Praticamente a metade dos ingressantes no Curso de Graduaçāo em Enfermagem era completamente contra a prática do aborto $(53,73 \%)$ e os 
motivos mais apontados para isto foram os relacionados, em primeiro lugar, à obrigatoriedade de aceitação na ocorrência de uma gravidez, só colocando como lícitas as formas controladoras da fecundidade através dos métodos anticoncepcionais $(20,89 \%)$ e, em segundo lugar, os motivos relacionados a valores humanitários ou religiosos que consideram o aborto como crime ou agressão à natureza $(14,93 \%)$.

Outra parcela grande desses estudantes $(41,59 \%)$ aceitava a prática do aborto sob determinadas condiçóes. As mais citadas foram: em casos de gravidez resultante de estupro ou violência sexual $(14,93 \%)$; problemas económicos (8,96\%); gravidez de alto risco materno ou malformaçáo fetal $(7,46 \%)$.

Apenas uma minoria $(4,48 \%)$ declarou-se a favor do aborto para outras pessoas, embora admitindo que pessoalmente não o faria, ou seja, condenando-o por vias indiretas (Tabela 1).

\section{O posicionamento dos formandos sobre o aborto}

Entre os formandos, a maioria também se declarou ou totalmente contra o aborto ou aceitando-o sob determinadas condiçōes $(64,3 \%)$ embora, diferentemente do grupo anterior, tenha havido uma parcela maior que tenha se declarado completamente a favor do aborto $(23,8 \%)$.

Quanto aos que aceitavam esta prática sob determinadas condiçōes, os posicionamentos qualitativamente näo diferiram daqueles dos ingressantes, tendo sido citados praticamente os mesmos motivos (estupro, problemas financeiros, problemas de saúde da mulher, possibilidade de problemas congênitos, etc) - Tabela 2.

\section{Reflexōes sobre os resultados das investigaçōes}

Embora num primeiro momento se perceba uma tênue diferença entre os posicionamentos dos dois grupos de estudantes, numa reflexâo mais aprofundada, o que se observa é que, de uma maneira geral, eles pouco ou quase nada diferiram daquilo que a superestrutura jurídico-político-ideológica da sociedade (aqui representada pela legislaçāo, pelos valores morais ou religiosos), coloca como lícito ou ilícito em relação à prática do aborto.

A maioria dos estudantes assume, em conformidade com os processos que ocorrem na sociedade como um todo, uma atitude de pré-julgamento em relação à prática do aborto, não garantindo à mulher o direito de decidir livremente sobre isto, de acordo com a sua situação peculiar.

Verificar que nảo existe praticamente diferença entre os posicionamentos dos estudantes ingressantes e dos quase egressos do Curso de Graduaçāo em Enfermagem, pode levar a crer que este curso ofereceu poucas oportunidades para que o estudante repensasse criticamente sua posiçāo diante da realidade, para possibilitar, no futuro, uma prática profissional reflexiva e 
transformadora ao invés de reiteradora da posiçäo e da ideologia da classe dominante.

\section{CONCLUSÃO}

Embora os estudos realizados apresentem limitaçōes quanto à metodologia utilizada, as autoras verificaram que o posicionamento dos estudantes em relação ao aborto pouco diferiu do posicionamento das suas classes sociais de origem (do setor dominante) em relação a esta prática social.

A análise dos dados permite concluir que, durante o curso de formação destes futuros enfermeiros, nảo houve oportunidades para o aprofundamento da reflexão crítica que propiciasse a consolidação de uma opiniāo mais fundamentada cientificamente, relacionando-a com os demais aspectos da sexualidade humana, bem como o entendimento da inserção da mulher na sociedade.

FONSECA, R. M. G. S. da; EGRY, E. Y. The reflex of the dominant ideology on the nursing students position concerning the abortion. Rev. Esc. Enf. USP., v.28, n.1, p. 50-8, Apr., 1994.

A new prism is used to re-analyse the results of two investigations developed by the authors with nursing students, concerning their position about the abortion. As they discuss the questions and the limits of the previous investigation methodology, they also show the relevance of an expanded understanding of the theme, through its articulation with the dominant ideology.

UNITERMS: abortion, ideology, nursing teaching.

\section{REFERÊNCIAS BIBLIOGRÁFICAS}

BERTOLOZZI, M.R. Pacientea com tubereubae pulmonar no Município de Taboīo da Serra: perfil e representaçöes sobre a asoisténcia prestada nas unidadeo básicas de saúde. Sāo Paulo, 1991. Dissertaçáo(Mestrado). Faculdade de Saúde Pública, Universidade de Sáo Paulo.

BRONFMAN, M.; TUIRÁN, R. La desigualdad social ante la muerte: claseo sociales y mortalidad en la niñez. Cuad.Med.Soc., n. 29/30, p.53-75, 1984.

EGRY, E.Y. Opiniāo dos graduandos de enfermagem sobre algumas práticas seruais. Rov Esc.Ent.USP., v.19, n.2, p.121-6, 1985.

FERREIRA, A.B. de H. Novo dicionfrio da lingun portuguesa. 2ed. Rio de Janeiro, Nova Fronteira, 1986. 
FONSECA, R.M.G.S. da. A prtitica anticoncepcional de estudantes de enfermagem. São Paulo, Escola de Enfermagem da USP, 1985. 120p. (Relatório de Pesquisa).

Mulher, reproduçâo biolóçica e classe social: a compreensāo do nexo coesivo através do estudo dialético do perfil reprodutivo biológico de mulheres atendidas nas Unidadeo Básicas de Saúde. São Paulo, 1990. 336p. Tese(Doutorado). Escola de Enfermagem, Universidade de Sảo Paulo. 
Tabela 1 - Distribuiçào dos eatudantes ingressantes no Curwo de Graduaçāo em Enfermagem segundo a opiniảo sobre a prática do aborto.

\begin{tabular}{|lll}
\hline Opiniāo & n & q
\end{tabular}

\section{Contra}

é totalmente contra; a pesoou deve evitar fillhoo antes de engravidar ser evitado; ó revoltante, a criença é produto do amor; ó totalmente contra a natureza

. ó contra: a pesson deve asoumir o que faz, ser respontivel

- é totalmente contra

- é contra porque é violéncia à mulher e à criança

A favor

- "pesocalmente nâo faria, mas é uma forma de contracopfío como outra qualquer, so a pesson eotí consciente do que faz"

\section{vub-total}

\section{Aceitável em algumas situaçōes}

. "é um recurso extremo que só deve ser utilizado em momontos dificois" é perigosa, desumano, mas permisaível quando nio ha outra alternativa (eotupro)

- no caso de nūo ter condiçöes para criar of fllho; é indesejado, ou rejeitado

- só aceitível em cascos de risco materno ou malformagäo fetal

- em casco muito graves de risco materno

- a favor quando náo tiver condiçöes para criar o filho e contra porque prejudica a mulher

$1 \quad 1,49$

. outras razōes

\begin{tabular}{cccc|}
\hline sub-total & 27 & 41,59 \\
\hline total & 67 & 100,00 \\
\hline
\end{tabular}

Font: (FONSECA t895) 
Tabela 2 - Distribuiçāo dos formandos do Curao de Graduaçào em Enfermagem segundo a oplniāo sobre o aborto

\begin{tabular}{|c|c|c|}
\hline Opinióes & n & $9 c$ \\
\hline Completamente a favor & 10 & 23,80 \\
\hline Completamente contra & 11 & 26,20 \\
\hline Nĩo tem opiniáo & 5 & 11,69 \\
\hline 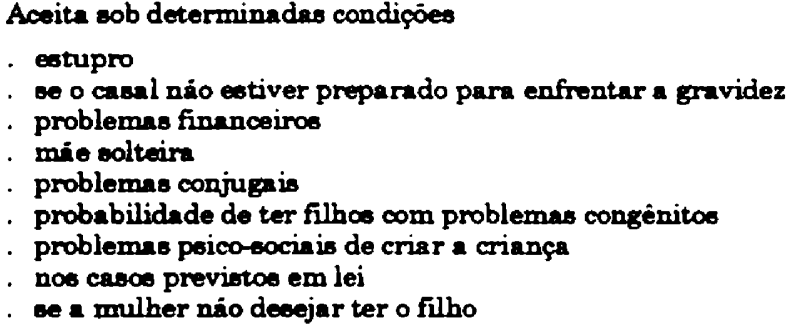 & 16 & 38,10 \\
\hline
\end{tabular}

Total

42

100,0

Fonte: (EGRY, 1805) 